University of Nebraska - Lincoln

DigitalCommons@University of Nebraska - Lincoln

\title{
$5-2011$
}

\section{Enigmatic Ornamentation Eases Male Reliance on Courtship Performance for Mating Success}

\author{
Eileen Hebets \\ University of Nebraska - Lincoln, ehebets2@unl.edu \\ Jay A. Stafstrom \\ University of Washington, jstaf@uw.edu \\ Rafael L. Rodriguez \\ University of Wisconsin-Milwaukee, rafa@uwm.edu \\ Dustin J. Wilgers \\ University of Nebraska-Lincoln, wilgers.spider@gmail.com
}

Follow this and additional works at: https://digitalcommons.unl.edu/bioscihebets

Part of the Behavior and Ethology Commons

Hebets, Eileen; Stafstrom, Jay A.; Rodriguez, Rafael L.; and Wilgers, Dustin J., "Enigmatic Ornamentation Eases Male Reliance on Courtship Performance for Mating Success" (2011). Eileen Hebets Publications. 40.

https://digitalcommons.unl.edu/bioscihebets/40

This Article is brought to you for free and open access by the Papers in the Biological Sciences at DigitalCommons@University of Nebraska - Lincoln. It has been accepted for inclusion in Eileen Hebets Publications by an authorized administrator of DigitalCommons@University of Nebraska - Lincoln. 
Published in Animal Behaviour 81:5 (May 2011), pp. 963-972; doi: 10.1016/j.anbehav.2011.01.023

Copyright (C) 2011 The Association for the Study of Animal Behaviour; published by Elsevier Ltd. Used by permission.

Submitted September 14,2010; revised October 21, 2010; accepted January 5, 2011; published online February $22,2011$.

\title{
Enigmatic Ornamentation Eases Male Reliance on Courtship Performance for Mating Success
}

\author{
Eileen A. Hebets, ${ }^{1}$ Jay A. Stafstrom, ${ }^{1}$ Rafael L. Rodriguez, ${ }^{2}$ and Dustin J. Wilgers ${ }^{1}$ \\ 1. School of Biological Sciences, University of Nebraska-Lincoln \\ 2. Department of Biological Sciences, University of Wisconsin-Milwaukee \\ Corresponding author - E. A. Hebets, School of Biological Sciences, University of Nebraska-Lincoln, 348 Manter Hall, Lincoln, NE 68588, U.S.A.
}

J. A. Stafstrom is now at the Department of Psychology, University of Washington, 119A, Guthrie Hall, Box 351525, Seattle, WA 98195, U.S.A.

R. L. Rodriguez is at the Department of Biological Sciences, University of Wisconsin-Milwaukee, Lapham Hall S181, P.O. Box 413, 3209 N Maryland Avenue, Milwaukee, WI 53201, U.S.A.

\begin{abstract}
Female preferences are frequently invoked to explain the widespread occurrence of elaborate male ornaments, yet empirical data demonstrating such preferences are sometimes equivocal or even contradictory. In the wolf spider Schizocosa stridulans, despite evidence of strong female choice, prior research has been unable to link the conspicuous sexually dimorphic foreleg ornamentation of males to their mating success. We conducted three experiments aimed at determining the function of this previously enigmatic ornamentation. Our first two experiments used males with phenotypically modified foreleg phenotypes in simple and complex mating environments in order to examine the relationship between the presence/absence of ornamentation and male mating success. In both experiments, we found no relationship: courtship rate was the sole predictor of mating success. In a third experiment, we used males with naturally varying foreleg ornamentation in mating trials. Ornamentation was subsequently quantified and we again examined the factors influencing male mating success. As in our first two experiments, we found courtship rate to be a good predictor of mating success. Additionally, we discovered that foreleg ornamentation and courtship rate interact to influence male mating success. At low courtship rates, males with more foreleg ornamentation have a mating advantage, whereas at high courtship rates, males with less foreleg ornamentation have a mating advantage. We discuss several potential explanations for these results. In summary, we provide the first evidence of a benefit of foreleg ornamentation in male $S$. stridulans and suggest that this benefit is realized by the interaction between ornamentation and courtship rate.
\end{abstract}

Keywords: amplifier, efficacy, intersignal interaction, mate choice, motor performance, multimodal signaling, sexual selection

Courtship songs and dances are among the most spectacular animal displays in existence. In many organisms, these displays are associated with intricate structures, conspicuous coloration, specific pigment patterns and/or other forms of sexual ornaments. The widespread occurrence of such elaborate male secondary sexual traits has both intrigued and baffled scientists for centuries and led Charles Darwin to develop his theory of sexual selection (Darwin 1871; reviewed in Andersson 1994). Darwin's solution, in part, to the existence of animal ornaments was the proposal that such traits as the peacock's tail evolved in response to selection via female choice. Indeed, multiple studies have demonstrated that female peahens prefer males with elaborate trains (Petrie et al. 1991; reviewed in Loyau et al. 2008), but others have failed to find evidence that the peacock's train is a current target of female mate choice (Takahashi et al. 2008). Some other empirical studies using other animal groups have also failed to find support for the hypothesis that male ornaments are currently under intersexual selection (e.g. great snipe, Gallinago media: Saether et al. 2000; wolf spider, Schizocosa uetzi: Shamble et al. 2009; red-winged blackbird, Agelaius phoeniceus: Westneat 2006). Importantly, sexual selection is not the only factor influencing sexual dimorphism, and not all differences between the sexes should be considered sexual ornaments. Furthermore, assuming that the traits under question are indeed ornaments, the negative results obtained in the above-mentioned studies cannot reject the possibility that past intersexual selection has led to the evolution of elaborate male ornaments. None the less, in some cases, more inclusive analyses of display characteristics may lend new insight into current targets of intersexual selection.

Elaborate sexual ornaments often accompany complex movements during animal displays (Zuk et al., 1995; Backwell et al., 1999; Hebets and Uetz, 2000; Madsen et al., 2004; Loyau et al., 2005; Murai and Backwell, 2006), making it feasible for selection to act on interactions between display properties and ornament characteristics 
(Kodric-Brown and Nicoletto, 2001; Candolin, 2003; Hebets and Papaj, 2005; Smith et al., 2009). An example of such naturally selected interactions is in the garter snake, Thamnophis ordinoides, where it is the combination of antipredator behavior and color patterns that is under selection (Brodie 1992). Selection that favors such combinations of morphological and behavioral traits (i.e. correlational selection; Lande \& Arnold 1983) is certainly not uncommon and has been well documented across animal groups (reviewed in Sinervo \& Svensson 2002). Similarly, the importance of trait combinations and potential interactions is being realized in recent studies focusing upon the function(s) of signal components and signal combinations in animal communication. For example, the wattle of male junglefowl, Gallus gallus, interacts with movement during tidbitting to increase the conspicuousness of the visual display (Smith et al. 2009); and seismic courtship signaling of the wolf spider Schizocosa uetzi alters a female's visual attention, making visual signaling relevant only in the presence of seismic signaling (Hebets 2005). Similar such interactions have been documented in other taxonomic groups as well, and intersignal interactions are likely to be more common than has been previously recognized (reviewed in Hebets and Papaj, 2005; Bro-Jorgensen, 2010). In line with the potential prevalence of interacting signals, it has recently been suggested that most sexual ornamentation evolved secondarily, via its interaction with movement displays (Byers et al. 2010).

Like many other animal taxa, males of several species of Schizocosa wolf spider engage in active, ritualized movements during courtship, often involving waving and tapping of ornamented forelegs (reviewed in Stratton 2005). While early Schizocosa studies focused on the relationship between ornamentation and female choice (McClintock and Uetz, 1996; Scheffer et al., 1996; Hebets and Uetz, 2000; Uetz and Roberts, 2002; Hebets, 2005, 2008; Hebets et al., 2006; Uetz and Norton, 2007), more recent studies have highlighted the importance of these active displays, as courtship rate has been shown to influence male mating success across multiple species of wolf spider (Kotiaho et al., 1998a; Parri et al., 2002; Rypstra et al., 2003; Delaney et al., 2007; Gibson and Uetz, 2008; Lomborg and Toft, 2009; Shamble et al., 2009; Rundus et al., 2010, 2011). Female Schizocosa are considered mostly monandrous (Norton \& Uetz 2005), and previous work has documented strong female mate choice across species (e.g. McClintock and Uetz, 1996; Scheffer et al., 1996; Hebets and Uetz, 2000; Hebets, 2003, 2005). Additionally, extensive variation exists among species in terms of the complexity of their courtship displays and associated secondary sexual traits (reviewed in Stratton, 2005; Framenau and Hebets, 2007), making them ideal focal taxa for studies exploring female choice and its influence on male reproductive behavior and associated morphologies.

In S. stridulans Stratton 1991, upon sexual maturation, males develop black coloration on their foreleg tibiae, patellae, and a portion of their foreleg femora, and very small black brushes of hair on their foreleg tibiae (Stratton, 1991, 2005). This foreleg pigmentation is fixed at maturation (Foelix 1996) and is lacking in mature females. During courtship, in addition to the production of a multicomponent seismic signal, males generate visual leg waves in which their ornamented forelegs are tapped asynchronously on the substrate (Stratton, 1991, 1997; Elias et al., 2006; for video see Supplementary Material in Hebets 2008). Female choice determines male reproductive success in $S$. stridulans, and seismic signaling has been shown to be the dominant signal in male courtship, being both necessary and sufficient for successful copulation; while visual signaling appears neither necessary nor sufficient (Hebets 2008). Previous studies found no influence of the visual signaling environment on mating success, suggesting that the presence/absence of visual signaling (and thus male ornamentation) is not crucial to male mating success (Hebets 2008). In addition, video playback studies revealed that females only distinguish between male foreleg phenotypes (e.g. degree of ornamentation) in the absence of a seismic signal (Hebets 2008), which represents an unrealistic or, at least, an uncommon scenario of a female's exposure to male courtship in nature. Despite the conspicuous visual foreleg ornamentation and associated leg movements during $S$. stridulans courtship, the function of male foreleg ornamentation has, until now, remained obscure.

The present study expands on these earlier works by more directly testing the relationship between male ornamentation and mating success in $S$. stridulans. To do this, we conducted three separate experiments: the first two experiments used males with phenotypically modified foreleg phenotypes (unornamented versus ornamented), while our third experiment used males with naturally varying foreleg phenotypes. In all experiments, females and males were allowed to freely interact, enabling us to directly assess male mating success.

\section{Methods \\ Spiders}

Immature female and male $S$. stridulans were collected at night on April 14-16, 2006, (experiment 1) and May 6-7, 2009 (experiments 2 and 3) in Panola County, MS, U.S.A. Spiders were housed individually in the laboratory under a 12:12 h light:dark cycle and were provided two to three crickets twice per week and a constant source of water.

\section{Experiment 1: Foreleg Ornamentation and Male Mating Success}

To test the importance of foreleg ornamentation in male reproductive success directly, we artificially removed ornamentation in a subset of males and compared their reproductive success to that of artificially ornamented males. In the summer of 2006, a total of 38 males ranging in age from 12 to 30 days postmaturation (mean $\pm \mathrm{SE}=21 \pm 5$ days) and 38 females ranging in age from 16 to 28 days postmaturation (mean $\pm \mathrm{SE}=21.34 \pm 0.41$ days) were each used once in mate choice trials. Upon maturation, males were haphazardly assigned to one of two treatments (i.e. phenotype manipulations): (1) unornamented forelegs $(N=22)$, first pair of walking legs (forelegs) was painted brown, fully covering all naturally occurring pigmentation; (2) artificially ornamented forelegs $(N=16)$, first pair of forelegs was painted black, fully covering all naturally occurring pigmentation. Painting was done with nail polish, and in both treatments, we painted only segments of the male's forelegs (the legs used in courtship displays). In all subsequent mating trials, a small piece of filter paper $(\sim 1 \times 1 \mathrm{~cm})$ was painted with a stripe of both brown and black nail polish and was placed on the floor of the arena to control for potential odor effects across treatments.

Bronze ice (CoverGirl 150, Procter \& Gamble, Cincinnati, OH, U.S.A.) nail polish was used to paint legs brown, while black crème nail polish (Wet 'n' Wild 424, Markwins Beauty Products Inc., City of Industry, CA, U.S.A.) was used for painting legs black. Despite potential disadvantages of using nail polish (Rutledge et al. 2010), previous studies have successfully utilized this manipulation to address questions of female mate choice in Schizocosa wolf spiders (Hebets, 2003; Rutledge et al., 2010). Manipulations consisted of painting the tibiae, patellae and the distal portion of the femora of the assigned legs. During painting, individual spiders were placed into a Ziploc bag with a bottom corner cut. In an attempt to escape, males naturally place their legs through the cut corner. Once extended through the open hole, the males' legs were then painted using a small paintbrush.

Mating trials took place in circular transparent acetate arenas measuring $13 \mathrm{~cm}$ in diameter and $7.5 \mathrm{~cm}$ in height. The bottom 
of each arena was lined with Whatman No. 1 filter paper, providing a substrate through which seismic signals could readily transmit. White paper was taped around the outside of the arenas to provide both visual isolation and a high contrast backdrop. Females were placed in the arena and allowed to acclimate for $1 \mathrm{~h}$, after which time a mature male was introduced. Female-male pairs were allowed to interact for $30 \mathrm{~min}$, during which time we recorded the following behaviors in real time: time to first courtship, number of double taps, presence/absence of copulation and cannibalism, and time to copulation. In this experiment and all subsequent experiments, a 'double tap' refers to a single bout of asynchronous foreleg tapping, incorporating more than one individual foreleg tap.

\section{Experiment 2: Foreleg Ornamentation in a Heterogeneous Signaling Environment}

In our second experiment, we tested whether ornamentation influenced male mating success in more complex signaling environments. If, for example, ornamentation functions to increase courtship detectability, one might predict reduced times to copulation and/or increased mating success for more ornamented males in more heterogeneous signaling environments. To test this, in the summer of 2009 , similar to experiment 1 , we created two male phenotypes: (1) unornamented forelegs (unnatural phenotype, brown forelegs) and (2) ornamented forelegs (natural phenotype, black forelegs). In contrast to experiment 1 , the two foreleg phenotypes were achieved via painting with brown craft paint (ANITA'S All Purpose Acrylic craft paint, 11044 Coffee, Synta Inc., Clarkston, GA, U.S.A.) instead of nail polish. Manipulations consisted of painting either the first (unornamented males) or the second (ornamented/natural foreleg males) pair of walking legs brown. In the unornamented foreleg treatment, the tibiae, patellae and distal portion of the femora of a male's forelegs were painted brown, fully covering all natural pigmentation. In the ornamented foreleg group, the tibiae, patellae and distal portion of the femora of a male's second pair of walking legs were painted brown, leaving their forelegs with natural pigmentation. Ultimately, unornamented males had their first pair of walking legs painted, whereas ornamented/natural foreleg males had their second pair of walking legs painted, enabling us to control for both the process of painting and the odor of the paint itself. Painting was done while males were restrained in Ziploc bags as described above. Males were able to successfully groom off the paint within $4 \mathrm{~h}$ of painting and thus, males were painted $2 \mathrm{~h}$ prior to the start of trials.

Mating trials took place in larger plastic arenas measuring $20.5 \mathrm{~cm}$ diameter $\times 7.5 \mathrm{~cm}$ height. To increase the complexity of the signaling environment and to decrease the signal-to-noise ratio, we placed a piece of brown construction paper at the bottom of the arena as a low-contrast signaling substrate. We printed a color photograph (LaserJet printer, HP 4650dn) of leaf litter taken from the ground level (i.e. a spider's eye view) at the collection site and taped it around the edge of the arena, providing a natural backdrop to the courting males. Five to seven dry leaves, also collected from the collection site, were placed in the arena to provide additional heterogeneity and natural substrate for signaling. Ultimately, the goal was to construct an arena that semirealistically replicated the complexity of the natural signaling environment for S. stridulans. At the end of each mating trial, leaves were removed and reallocated to testing arenas for subsequent trials that day. Leaves, in all probability, had female silk from the field in addition to accumulated female silk during our trials. Regardless, trials with unornamented and ornamented males were always paired and we saw no effect of trial time on outcome, making it unlikely that female silk could explain any results. All arenas were swabbed with alcohol between trials.
Females $(N=44)$ were randomly assigned a male treatment (unornamented foreleg versus ornamented/natural foreleg). Prior to trials, females were weighed and placed in the arena for $1 \mathrm{~h}$, during which time they could acclimate and deposit fresh pheromone-laden silk. At the start of a trial, males were placed in the appropriate arena and pairs were observed for $40 \mathrm{~min}$. During the trial, the following real-time measurements were taken: time to first courtship, number of double taps, presence/absence of copulation and cannibalism, and time to copulation. As in experiment 1 , each individual was used only once.

\section{Experiment 3: Natural Foreleg Ornamentation and Male Mating Success}

Our first two experiments found no influence of the presence/absence of ornamentation on male mating success (see Results, experiments 1 and 2). However, both experiments involved artificial manipulations of male ornamentation, potentially decoupling important or relevant interactions between natural ornamentation and other traits. Thus, our third experiment took a more basic approach to exploring the function of foreleg ornamentation by allowing it to naturally interact with other traits and examining the effect on male mating success.

Unmanipulated males that varied naturally in ornamentation were used in single-choice mating trials. All males and females were mature virgins and were used only once. As in experiment 2, mating trials took place in circular plastic arenas measuring $20.5 \mathrm{~cm}$ diameter $\times 7.5 \mathrm{~cm}$ height. Similar to experiment 1 , we examined natural ornamentation and male reproductive success in a simple environment with a high signal-to-noise ratio. Such a simple signaling environment enabled us to detect interactions between courtship components, as all components were probably continuously accessible to females. A piece of white Whatman No. 1 filter paper lined the bottom of the arena and a piece of white paper lined the sides. Mate choice females were placed in the arena $5 \mathrm{~min}$ prior to the start of the trial. Males were then placed in the arena and the female-male pair was allowed to interact for $30 \mathrm{~min}$. During mating trials we scored the following behaviors in real time: time to first courtship, number of double taps, presence/absence of copulation and cannibalism, and time to copulation.

\section{Quantification of Ornamentation}

Subsequent to mating trials, males were sacrificed via freezing and preserved in 70\% ETOH. After approximately 6 months, male foreleg ornamentation was quantified following Shamble et al. (2009). Briefly, one foreleg from each male was removed from the ETOH, air dried and placed lateral side up on a glass slide. Each slide was then photographed using a Leica DM 4000 B microscope with a Diagnostic Instruments, Inc. Spot Flex digital camera, under a 1.25× objective. Each slide was lit from the side and above via dual fiber optic lights (Lumina $150 \mathrm{~W}$ ) and the lighting remained constant across all photographs as all photographs were taken in one sitting.

Digital photographs were imported into Adobe Photoshop CS2 and converted into grayscale. The areas of the tibia, patella and metatarsus were measured by selecting each segment with the polygonal lasso tool and recording the number of pixels within the selection. A Wacom Bamboo pen and tablet were used to ensure the highest selection accuracy. After selection of each leg segment, we recorded the mean image intensity (a numerical reading where 255 is white and 0 is black). The number of pixels in the tibia, patella and metatarsus covered by color were then determined using the threshold command, which converts all pixels lighter than a given threshold white and those darker, black. The threshold was set for all segments at one standard deviation darker than the mean tibia color, the darkest fore- 
leg segment. We used an image intensity threshold of 17 . Once the two-tone threshold image was created, we calculated the percentage of each segment covered by dark color by dividing the number of black pixels by the total number of pixels.

Schizocosa stridulans pigmentation extends onto the femur (Stratton 1991). Because of leg damage near the femur-trochanter joint caused by leg removal, we were unable to measure percentage of pigmentation on the femur in the same manner as the previously described segments. Instead, femur pigment was quantified by measuring how far pigmentation extended proximally onto the leg segment. Using the threshold command, the segment was turned into a twotone image using identical methods used on the tibia, patella and metatarsus. The middle of the intersection point where the patella joins the femur was selected and a line was drawn from that point to the most proximal point of dark pigmentation on the femur. The length of the line was measured in pixels and then divided by the total length of the femur, also in pixels, giving a proportion of how far dark pigmentation extended onto the femur.

To analyze the natural variation in foreleg ornamentation $(N=39)$, we conducted a principal component analysis on the covariance matrix of the following five traits: mean darkness of the tibia $(19.25 \pm 0.33$, scale dark to light $=0-255)$, percentage of the tibia pigmented $(23.2 \pm 2.7 \%)$, percentage of the patella pigmented $(5.34 \pm 1.3 \%)$, percentage of the metatarsus pigmented $(0.46 \pm 0.64 \%)$ and the proportional distance that the pigmentation extended onto the femur $(0.17 \pm 0.16 \%)$. Although S. stridulans was originally described as lacking foreleg brushes (Stratton 1991), a more recent morphological analysis indicates that tibial bristles are present (Stratton 2005). None the less, foreleg brushes are undetectable without the use of magnifying equipment, and thus, the present study focuses on pigmentation only. The first principal component (PC1), with an eigenvalue of 299.8, accounted for $86 \%$ of the variation in pigmentation pattern. In all subsequent analyses, we used PC1 as our ornamentation index. Pairwise correlations revealed that mean darkness of the tibia was negatively correlated with the remaining four traits; this was expected since lower mean darkness values indicate darker males. All other pairwise comparisons were positively correlated. Thus, high PC1 scores represent males with more ornamentation (e.g. low mean tibia scores, high percentages of the tibia, patella and metatarsus pigmented and a large proportional distance of pigmentation onto the femur).

\section{Statistical Analyses}

In all three experiments, courtship rate was calculated as the total number of leg tap bouts divided by the total duration of time spent courting. The time from first courtship to copulation was also calculated and used as a proxy of male reproductive success, which is probably relevant in nature given the frequent high densities of natural populations.

To determine which variables were predictive of copulation success (copulation versus no copulation), we used a nominal logistic regression model with predictor variables of courtship rate, male ornamentation, male weight and all pairwise interactions. To complement significance testing, we calculated effect sizes with confidence intervals for each of our predictor variables to gauge their magnitude of effect, as well as the precision of the estimate of this magnitude of effect (Nakagawa \& Cuthill 2007). Effect size statistics such as $r$ vary between 0 and 1 , and enable one to compare the strength of associations among variables. For our nominal logistic regression models, we calculated $\phi$ (phi), a statistic that is like $r$ in its interpretation, from the chi-square values generated for each predictor variable in our model (Cohen, 1988; Rosenthal, 1991). We calculated $\phi$ and its confidence intervals (CI) using freely available software (Table 4 in Nakagawa \& Cuthill 2007; es calculator: http://mason.gmu. edu/ dwilsonb/ma.html by David B. Wilson). Although an odds ratio is more frequently used as an effect size measure for logistic regression analyses, when an odds ratio is calculated for continuous predictor variables (e.g. courtship rate or male weight), it is not dimensionless (Nakagawa \& Cuthill 2007). Furthermore, since odds ratios are not bounded between 0 and $1, \phi$ is more readily comparable across studies. To confirm that $\phi$ provided accurate estimates of effect size, we also calculated effect size by converting each $P$ value to its standard normal deviate equivalent using a table of $Z$ values. We then calculated $r$ by taking the square root of $Z^{2}$ divided by $N$ (i.e. $\left.r=\sqrt{ }\left(Z^{2} / N\right)\right)$ (see Rosenthal 1991). In most cases, these two estimates gave very similar effect sizes; estimates differed somewhat in only four instances (courtship rate: $r=0.63$ versus $\phi=0.76$, Table 1 ; courtship rate: $r=0.59$ versus $\phi=0.82$; ornament*male weight: $r=0.07$ versus $\phi=0.12$, Table 3 ; courtship rate: $r=0.62$ versus $\phi=0.78$, Table $5)$. In all instances, $\phi$ was larger than $r$.

We used courtship rate, foreleg ornamentation and the interaction between the two in a standard least square regression to determine which variables influenced the time from first courtship to copulation. For a measure of effect size, we calculated $r$ and its CI for all independent variables using $t$ values provided by our regression model (see Nakagawa \& Cuthill 2007). When $r$ is calculated in this manner, it is often referred to as a partial correlation coefficient (Nakagawa \& Cuthill 2007). As above, these values were calculated using freely available software (Table 4 in Nakagawa \& Cuthill 2007; es calculator: http://mason.gmu.edu/ dwilsonb/ma.html by David B. Wilson).

All data were analyzed with JMP 8 (SAS Institute, Cary, NC, U.S.A.) and variables that were not normally distributed were transformed (square root or $\ln$ ) to meet assumptions of normality.

\section{Results}

\section{Experiment 1: Foreleg Ornamentation and Male Mating Success}

A nominal logistic regression model with predictor variables of presence/absence of ornamentation, male courtship rate (ln transformed), male weight and all pairwise interactions and the response variable of presence/absence of copulation was significant $\left(\chi_{6,31}{ }^{2}=23.58, R^{2}\right.$ $(U)=0.65, P=0.0006)$. The likelihood to copulate was dependent upon courtship rate (Figure 1a) but not on other variables or interactions (Table 1$)$. The magnitude of the effect of courtship rate on copulation success was quite large $(\phi=0.76$; Table 1$)$.

Trials incorporating males with black versus brown painted forelegs did not differ in average female age (ANOVA: $F_{1,36}=2.78$, $P=0.1$ ) or average male weight (Kruskal-Wallis test: $\chi_{1}^{2}=0.44$, $P=0.51)$. Males from the two treatments also did not vary significantly in their average courtship rate (ANOVA: $F_{1,36}=3.7, P=0.06$ ). No male that courted at a rate lower than 0.87 double taps $/ \mathrm{min}$ achieved copulation, suggesting a threshold for female acceptance (data included in Figure 1c).

Table I. Nominal logistic regression model examining copulation success for males with phenotypically modified foreleg phenotypes (ornamented: forelegs painted black; unornamented: forelegs painted brown; experiment I)

\begin{tabular}{llllc}
\hline Source & $\chi_{1}{ }^{2}$ & \multicolumn{1}{c}{$P$} & $\phi$ & $\mathrm{Cl}$ \\
\hline Courtship rate (In transformed) & 21.66 & $<0.000 \mathrm{I}$ & 0.76 & $0.52-0.89$ \\
Ornament (presence/absence) & 0.486 & 0.49 & 0.113 & $-0.20-0.41$ \\
Male weight & 1.2 & 0.27 & 0.18 & $-0.014-0.46$ \\
Courtship rate*ornament & 0.005 & 0.94 & 0.012 & $-0.30-0.32$ \\
Courtship rate*male weight & 0.55 & 0.46 & 0.12 & $-0.20-0.41$ \\
Ornament*male weight & 0.34 & 0.56 & 0.095 & $-0.22-0.41$ \\
\hline
\end{tabular}

Overall model was significant (see Results). 
A standard least square regression was used to test for the effects of presence/absence of ornamentation, male courtship rate and an interaction between the two on the time from first courtship to copulation. Our overall model was not significant $\left(F_{3,3}=1.1, r^{2}=0.52, P=0.47\right)$. We found no effect of foreleg ornamentation, courtship rate (ln transformed), and no interaction between the two on the time from first courtship to copulation (Table 2). Despite the lack of significance, the presence/absence of ornamentation may be important in influencing the time from first courtship to copulation, as the $F$ ratio was greater than 1 and our calculated effect size $r$ was 0.58 (Table 2); this suggested importance of ornamentation must be tempered by the CI of $r$, which overlapped zero. There is thus ambiguous evidence in favor of an effect of the presence/absence of ornamentation (see Discussion).

\section{Experiment 2: Foreleg Ornamentation in a Heterogeneous Signaling Environment}

We used 22 males with natural forelegs and 22 males with unornamented forelegs in interactions with 44 females. A nominal logistic regression model that included predictor variables of male foreleg ornament (unornamented versus ornamented), male courtship rate (square-root transformed), male weight and all pairwise interactions and the occurrence of copulation as the response variable was significant $\left(\chi_{6,37}{ }^{2}=33.89, R^{2}(U)=0.58, P<0.0001\right)$. The likelihood to copulate was dependent on male courtship rate (square-root transformed; Figure 1b), but not on other variables or interactions (Table 3 ). The magnitude of the effect of courtship rate on copulation success was again, quite large $(\phi=0.82$; Table 3$)$.

A standard least square regression model that included male foreleg ornamentation (unornamented versus ornamented), male courtship rate (square-root transformed) and an interaction between ornamentation and courtship rate as predictor variables and the time from first courtship to copulation (ln transformed) as the response variable was not significant $\left(F_{3,14}=1.87, r^{2}=0.29, P=0.18\right)$. We found no effect of foreleg ornamentation and no interaction between ornamentation and courtship rate on the time from first courtship to copulation. Despite the lack of significance in the model, courtship rate appeared to be important in influencing the time from first courtship to copulation, as our calculated effect size, $r$, was 0.51 (Table 4).

Table 2. Standard least square regression model examining time from first courtship to copulation for males with phenotypically modified foreleg phenotypes (ornamented: forelegs painted black; unornamented: forelegs painted brown; experiment I)

\begin{tabular}{llccc}
\hline & $F_{1,5}$ & $P$ & $r$ & $\mathrm{Cl}$ \\
\hline Courtship rate (In transformed) & 0.50 & 0.53 & 0.30 & $-0.58-0.86$ \\
Ornamentation (presence/absence) & 2.55 & 0.21 & 0.58 & $-0.30-0.93$ \\
Ornamentation*courtship rate & 0.09 & 0.79 & 0.12 & $-0.69-0.80$ \\
\hline
\end{tabular}

Overall model was not significant (see Results).

Table 3. Nominal logistic regression model examining copulation success for males with phenotypically modified foreleg phenotypes (ornamented: 2nd pair of legs painted brown; unornamented: Ist pair of legs painted brown) in complex signaling environments (experiment 2)

\begin{tabular}{lllll}
\hline Source & $\chi_{1}{ }^{2}$ & $P$ & $\phi$ & \multicolumn{1}{c}{$\mathrm{Cl}$} \\
\hline $\begin{array}{l}\text { Courtship rate } \\
\quad(\text { square-root transformed) }\end{array}$ & 29.27 & $<0.000 \mathrm{I}$ & 0.82 & $0.62-0.92$ \\
Ornament (presence/absence) & 0.0009 & 0.98 & 0.0045 & $-0.28-0.29$ \\
Male weight & 1.7 & 0.19 & 0.20 & $-0.1-0.46$ \\
Courtship rate*ornament & 0.35 & 0.56 & 0.089 & $-0.20-0.37$ \\
Courtship rate*male weight & 3.5 & 0.06 & 0.28 & $-0.0 \mathrm{I}-0.53$ \\
Ornament*male weight & 0.22 & 0.64 & 0.12 & $-0.17-0.40$ \\
\hline
\end{tabular}

Overall model was significant (see Results).
Painting appeared not to influence male courtship, as all males in our trials courted and courtship rate did not differ between male treatment groups (square-root transformed data: $F_{1,43}=0.03$, $P=0.86$ ). Courtship rate ranged from 0.06 to 5.6 double taps $/ \mathrm{min}$, and no male that courted at a rate lower than 0.93 double taps $/ \mathrm{min}$ was able to achieve copulation (data included in Figure 1c).

\section{Experiment 3: Natural Foreleg Ornamentation and Male Mating Success}

Male S. stridulans varied in their degree of foreleg ornamentation $(N=39)$. A nominal logistic regression model with a response variable of presence/absence of copulation and predictor variables of male ornamentation (PC1), male courtship rate (square-root transformed), male weight and all pairwise interactions was significant $\left(\chi_{6,32}{ }^{2}=32.45, R^{2}(U)=0.65, P<0.0001\right)$. The likelihood to copulate was dependent on courtship rate (square-root transformed; Figure 2), male weight, and on an interaction between courtship rate and ornamentation (PC1) (Table 5). Heavier males were more likely to copulate, as were males that courted at a higher rate. There was no correlation between male weight and courtship rate $\left(F_{1,37}=0.24, r^{2}=0.007\right.$, $P=0.62)$. The predictive value of male weight was largely driven by one large outlier $(0.058 \mathrm{~g})$. When this male was excluded, the difference in male weight between copulating and noncopulating males was not significant $\left(F_{1,36}=1.8, P=0.18\right)$.

Our results reveal that ornamentation interacts with courtship rate to influence male mating success. Before exploring this relationship, it is important to note that one noncopulating individual had a PC1 score well above the others $(\mathrm{PC} 1=53.17)$. When this individual was removed from the analysis, the results were unchanged (overall model: $\left.\chi_{6,31}{ }^{2}=32.07, R^{2}(U)=0.66, P<0.001\right)$. We continued to see a significant effect of the interaction between ornamentation and courtship rate on the likelihood to copulate $\left(\chi_{1}^{2}=10.74, P=0.001\right)$, demonstrating that our results were robust to this outlier.

To generate a graphical representation of the interaction between ornamentation, courtship and male mating success, which could facilitate its interpretation, we grouped males according to their degree of ornamentation. Specifically, we created three ornamentation categories based upon the normal distribution of PC1: (1) the bottom

Table 4. Standard least square regression model examining the time from first courtship to copulation success for males with phenotypically modified foreleg phenotypes (ornamented: 2nd pair of legs painted brown; unornamented: Ist pair of legs painted brown) in complex signaling environments (experiment 2)

\begin{tabular}{llllr}
\hline & $F_{1,16}$ & $P$ & $r$ & \multicolumn{1}{c}{$\mathrm{Cl}$} \\
\hline Courtship rate (square-root transformed) & 5.6 & $0.033^{*}$ & $0.5 \mathrm{I}$ & $0.06-0.79$ \\
Ornamentation (presence/absence) & 0.02 & 0.89 & 0.04 & $-0.44-0.49$ \\
Ornamentation*courtship rate & 0.42 & 0.53 & 0.16 & $-0.33-0.58$
\end{tabular}

Overall model was not significant (see Results).

* This model was not significant.

Table 5. Nominal logistic regression model examining copulation success for males with naturally varying foreleg ornamentation (experiment 3 )

\begin{tabular}{|c|c|c|c|c|}
\hline Source & $\chi_{1}{ }^{2}$ & $P$ & $\phi$ & $\mathrm{Cl}$ \\
\hline $\begin{array}{l}\text { Courtship rate } \\
\text { (square-root transformed) }\end{array}$ & 23.52 & $<0.000 \mid$ & 0.78 & $0.55-0.90$ \\
\hline $\mathrm{PCl}$ ornament & 1.0 & 0.31 & 0.16 & $-0.15-0.44$ \\
\hline Male weight & 4.9 & $0.03 *$ & 0.35 & $0.04-0.60$ \\
\hline Courtship rate*PCI ornament & 10.31 & 0.001 & 0.51 & $0.22-0.72$ \\
\hline Courtship rate*male weight & 0.47 & 0.49 & 0.11 & $-0.20-0.40$ \\
\hline $\mathrm{PCl}$ ornament*male weight & 0.0005 & 0.98 & 0.0036 & $-0.30-0.31$ \\
\hline
\end{tabular}

Overall model was significant (see Results).

* Upon removal of one outlier (see Results), male weight was no longer significant $(P>0.05)$. 

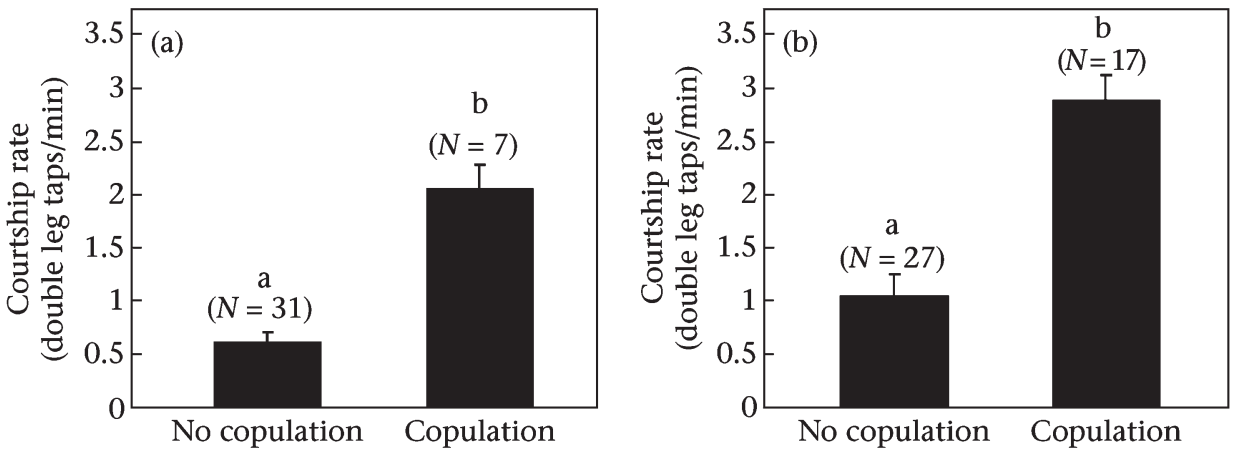

Figure I. Comparison of courtship rates of copulating versus noncopulating males. Courtship rate predicts copulation success in S. stridulans: (a) results from experiment I, simple environment; (b) results from experiment 2, complex environment. Different letters above bars indicate significant differences. (c) Distribution of male courtship rates (untransformed data), combined results of experiment I and experiment 2 . No male with a courtship rate of less than 0.87 double taps/min achieved copulation, indicating a threshold courtship rate for copulation success.

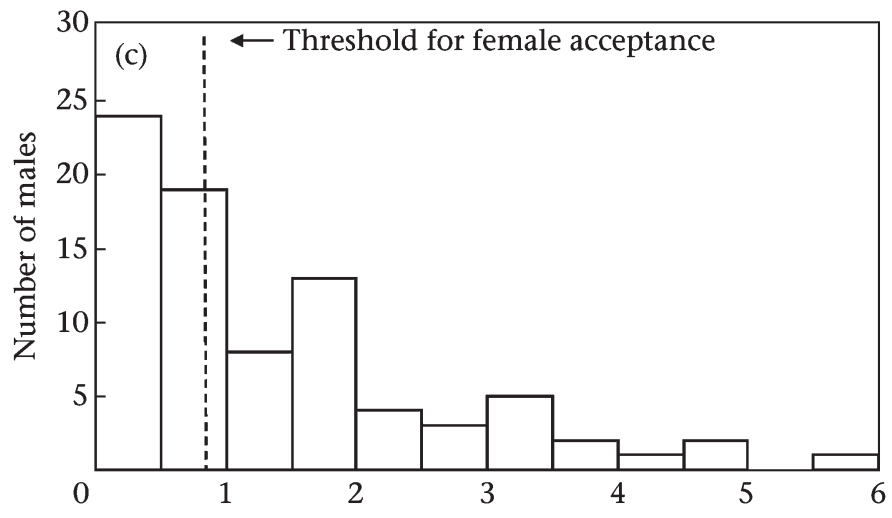

Observed courtship rate (double leg taps/min)

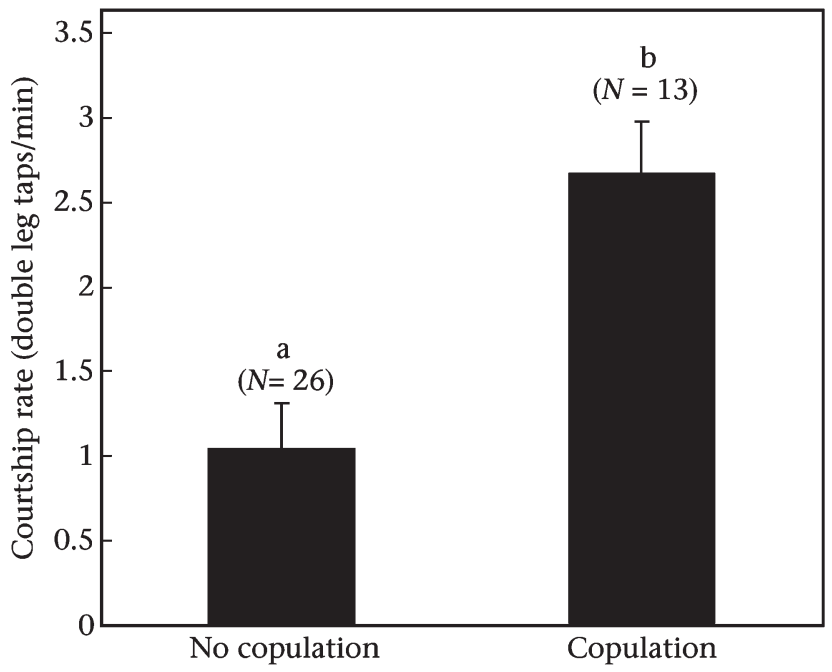

Figure 2. Courtship rates of copulating and noncopulating males of varying foreleg ornamentation (experiment 3). Different letters above bars indicate significant differences.

$25 \%$ of males (lightest/least ornamented quartile of males, $N=9$; Figure 3, small dashed grey line), (2) the middle $50 \%$ of males (middle two quartiles of males, $N=21$; Figure 3, large dashed black line) and (3) the top $25 \%$ of males (darkest/most ornamented quartile of males, $N=9$; Figure 3, solid black line). Given our confidence in courtship rate as a major factor influencing mating success (see $\mathrm{Ta}-$ bles 1,3 , \& 5), we graphed courtship rate as our independent variable and the probability of copulation as our dependent variable, and

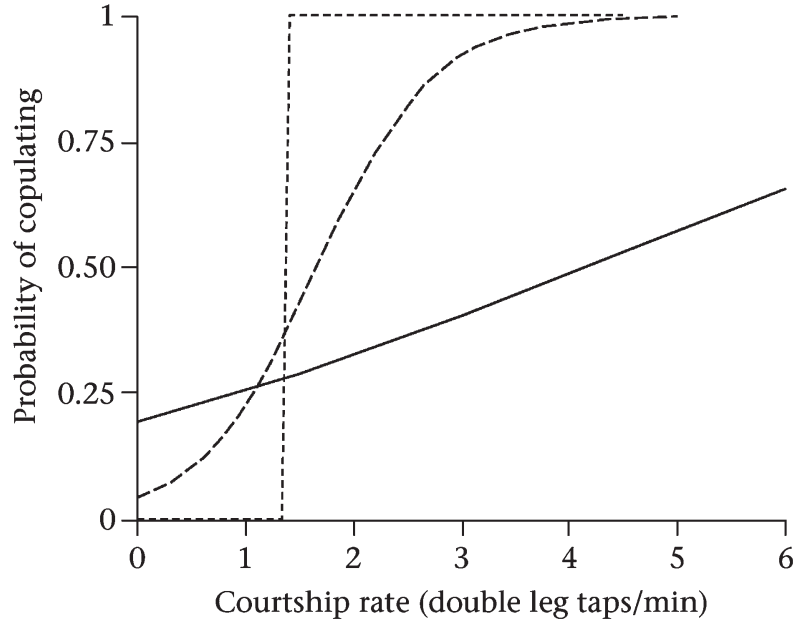

Figure 3. Probability of copulating by courtship rate (untransformed data) for males with varying degrees of foreleg ornamentation. Males were categorized into three groups based upon their ornamentation score (PCI). The relationship between courtship rate and the probability of copulating is shown for each group of males: $(\mathrm{I})$ the least ornamented quartile (small dashed grey line), (2) the middle two quartiles (large dashed black line) and (3) the most ornamented quartile (solid black line). The three lines indicate the probability of mating at a given courtship rate for each of the three ornamentation groups.

we plotted the relationship between courtship rate and probability of copulation for our three categories of males onto a single graph (Figure 3). Our resulting graph indicates that the most ornamented males had a mating advantage at low courtship rates, followed by males with mid-level ornamentation. In contrast, the least ornamented males had a $0 \%$ probability of mating below a courtship of $~ 1.3$ (Figure 3). The courtship rate threshold at which $50 \%$ of males achieved a mating varied for males in the three ornamentation categories 
Table 6. Standard least square regression examining the time from first courtship to copulation for males with naturally varying foreleg ornamentation (experiment 3)

\begin{tabular}{lllcl}
\hline & $F_{1,12}$ & $P$ & $r$ & $\mathrm{Cl}$ \\
\hline $\begin{array}{l}\text { Courtship rate } \\
\quad \text { (square-root transformed) }\end{array}$ & 2.17 & 0.17 & 0.39 & $-0.18-0.76$ \\
Ornamentation (presence/absence) & 0.20 & 0.66 & 0.13 & $-0.43-0.62$ \\
Ornamentation*courtship rate & 2.5 & 0.15 & 0.42 & $-0.15-0.77$ \\
\hline
\end{tabular}

Overall model was not significant (see Results).

(Figure 3). For males in the lightest and middle two quartiles, this courtship rate threshold was similar ( 1.3-1.5 double taps/min), but it was much larger for the darkest quartile of males ( $>4$ double taps/ min) (Figure 3).

A standard least square regression testing for the effects of the degree of ornamentation (PC1), courtship rate (square-root transformed) and an interaction between the two on the time from first courtship to copulation was not significant $\left(F_{3,10}=1.38, r^{2}=0.29\right.$, $P=0.31)$. We found no effect of ornamentation or courtship rate, and no interaction between the two on the time from first courtship to copulation (Table 6). None the less, our calculated effect sizes for courtship rate $(r=0.39$; Table 6$)$ and the interaction between ornamentation and courtship rate $(r=0.42$; Table 6$)$ suggest that both of these may influence the time from first courtship to copulation.

\section{Discussion}

Despite the possession of seemingly conspicuous, and sexually dimorphic, foreleg ornamentation by mature male $S$. stridulans wolf spiders, our results demonstrate that male mating success is independent of the presence/absence of ornamentation alone. Using males with manipulated foreleg phenotypes in mating trials across signaling environments of varying heterogeneity, we found no evidence that the presence/absence of ornamentation influences male reproductive success. There was no relationship between the presence/absence of ornamentation and copulation success and no significant relationship between the presence/absence of ornamentation and time from first courtship to copulation. In these first two experiments, however, male ornamentation was manipulated artificially. In a final experiment, we allowed for the degree of ornamentation to vary naturally and to interact with other male traits. In this final experiment, we found a significant interaction between the degree of ornamentation and courtship rate, the characteristic demonstrated throughout to be the most important for male mating success. This interaction reveals, for the first time for this species, potential benefits of male foreleg ornamentation. Importantly, however, it also implies associated mating costs. Specifically, our results suggest that males receive mating benefits due to ornamentation at low courtship rates, but suffer mating costs due to ornamentation at high courtship rates. Ultimately, the relationship between male ornamentation and mating success is more complex than previously appreciated. Our discovery of this complexity highlights the importance of both inclusive analyses of reproductive behavior that allow for interacting traits, and of direct examinations of the often assumed relationship between female mate choice and extravagant male ornaments.

Schizocosa stridulans male foreleg ornamentation does not directly influence female mate choice, making it unlikely that ornamentation itself is a direct target of intersexual selection. In addition to the lack of statistical support for a relationship between ornamentation and copulation success, the magnitude of the effect of ornamentation on copulation success, as seen in values of $\phi$, was relatively low as com- pared to that of courtship rate across all experiments (Tables 1, 3, \& 5). These results confirm earlier studies that more indirectly failed to find a relationship between male ornamentation and female reproductive behavior in S. stridulans (Hebets 2008). We suggest that male ornamentation is also unlikely to be the direct target of intrasexual selection. A mature male's behavior towards another male is superficially indistinguishable from that towards a female: males court and attempt to mount other males. Previous work on a closely related species $(S$. ocreata) has shown that the male signaling observed in male-male interactions (i.e. the same species-specific signaling used in male-female contexts) does not influence the outcome of these interactions (Delaney et al. 2007). Thus, although possible, it seems unlikely that male ornamentation functions in intrasexual encounters.

Male $S$. stridulans mating success was determined largely by courtship rate, and the magnitude of this effect was large across all experiments $(\phi>0.76)$. In our experiments, no male courting below 0.87 double taps/min was able to achieve a mating, suggesting that there is a minimum threshold above which a male must court in order to achieve copulation (Figure 1c). In addition, above the threshold, as courtship rate increased, a male's likelihood of copulating increased. Female preferences for male courtship rate have been documented for a wide range of animals including, but not limited to, orthopterans, homopterans and anurans (reviewed in Gerhardt \& Huber 2002), fiddler crabs (Backwell et al., 1999; Murai and Backwell, 2006), birds and mammals (reviewed in Byers et al. 2010), and wolf spiders (Kotiaho et al., 1998a; Parri et al., 2002; Rypstra et al., 2003; Delaney et al., 2007; Gibson and Uetz, 2008; Lomborg and Toft, 2009; Shamble et al., 2009; Rundus et al., 2010). Thus, our findings that female choice depends upon courtship rate and that higher courtship rates result in faster copulations in $S$. stridulans were not unexpected. Courtship behavior is costly for wolf spiders, as it is in other taxonomic groups (great snipe: Hoglund et al. 1992; field cricket: Hoback \& Wagner 1997; fiddler crab: Matsumasa \& $\mathrm{Mu}-$ rai 2005; mole cricket: Prestwich \& O'Sullivan 2005). A signaling male Hygrolycosa rubrofasciata increases its resting metabolic rate 22fold (Kotiaho et al. 1998b), and increased drumming results in higher mortality and significant weight loss (Mappes et al. 1996). Furthermore, courtship rate in numerous wolf spiders is condition dependent (Mappes et al., 1996; Kotiaho, 2000; Lomborg and Toft, 2009), increases predation risk (Kotiaho et al., 1998a; Lindstrom et al., 2006; Hoefler, 2008), and carries significant immunological costs (Ahtiainen et al., 2004, 2005). Given the high costs associated with courtship, courtship rate may provide a female with valuable information about a male's condition or quality. Unfortunately, we do not have information about the costs of male courtship performance in S. stridulans and/or the factors that may influence its expression.

Our results suggest that foreleg ornamentation in male S. stridulans reduces male reliance on courtship rate; more ornamented males can obtain copulations despite low courtship effort. This reduced reliance may effectively decrease the courtship threshold for male mating and/or may increase the probability of mating given courtship rates slightly above the threshold. This extrapolation is best appreciated by comparing males at the extreme ends of the ornamentation distribution (e.g. least ornamented versus most ornamented quartile of males, based upon PC1 scores; see Figure 3). At courtship rates less than approximately 1.3 double taps/min, the most ornamented males had a clear mating advantage over the least ornamented males, a probability of mating near $25 \%$ for the most ornamented versus a $0 \%$ probability of mating for the least ornamented males (bottom left corner of Figure 3). Importantly, this is the range of courtship rates that encompasses a majority of courting males (see Figure 1c). To elucidate further, the median courtship rate for males in experiments 2 and 3 was 1.59 and 1.27 double taps/min, respectively, demonstrating that close to half of our tested males courted at a rate lower than 
1.3 double taps $/ \mathrm{min}$. In experiment 1 , the median was only $0.66 \mathrm{dou}-$ ble taps/min, probably due to both a different collecting year (2006 versus 2009), as well as a different method of phenotype manipulation, which may have uniformly reduced male courtship performance. Ultimately, for a majority of males, despite the general importance of courtship rate for mating success, ornamentation can facilitate mating even at low courtship rates and thus ease a male's reliance on courtship performance.

In its interaction with courtship rate, ornamentation could influence either (1) the efficacy of courtship rate as a signal, for example, via its detectability or discriminability; or (2) the content, or interpretation, of courtship rate as a signal. We will briefly discuss a few hypotheses regarding the mechanisms underlying our observed interaction, noting that this is not an exhaustive list of possibilities and that future work is certainly needed to distinguish among them.

\section{Efficacy Effects}

In lieu of finding direct evidence of female choice for male ornamentation, previous authors have suggested that foreleg ornamentation functions to increase the detectability of Schizocosa male courtship signals in naturally complex signaling environments (Scheffer et al., 1996; Hebets and Uetz, 2000; Uetz et al., 2009). Our second experiment attempted to test this hypothesis explicitly, and found no support. An explanation of increased detectability would predict a decrease in the time to mating for more ornamented males and might also predict that more ornamented males courting at a higher rate would mate the fastest. In contrast to these predictions, we found no influence of ornamentation on time to copulation. None the less, the argument can still be made that our environment was not sufficiently complex or that our sample sizes were not large enough to detect an effect. To counter this argument, we point to the low effect size of ornamentation in our second experiment $(r=0.04$; Table 4$)$, yet acknowledge that future studies exploring this avenue further may prove fruitful. In fact, results from our first experiment, in which both unornamented and ornamented male forelegs were phenotypically manipulated, suggest that in a simple environment, the presence of ornamentation may influence the time from first courtship to copulation (ornamentation: $r=0.58$; Table 2). However, in this experiment, although not significant, males with brown painted forelegs tended to court at a lower rate than males with black painted forelegs. Given that courtship rate also appears to influence time to copulation (courtship rate: $r=0.30, r=0.51, r=0.39$; Tables $2,4, \& 6$, respectively), slight differences in courtship rate may explain why ornamentation appeared to influence time to copulation only in experiment 1 .

Foreleg ornamentation in S. stridulans has also previously been suggested to function as an amplifier of the visual display (Hebets \& Uetz 2000). Amplifiers act to increase a female's resolution power with respect to a trait of interest (e.g. courtship rate), and can evolve via female choice even if they are not themselves the direct target of choice (Hasson 1989). In S. stridulans, an amplifying function would be consistent with our lack of support for the hypothesis that ornamentation is a current target of female choice. Under an amplifier scenario, increased resolution power should result in more efficient assessment (especially in more heterogeneous signaling environments), resulting in decreased time to decision making, and thus decreased time from first courtship to copulation for more ornamented males. Our results do not support this prediction, as we found no evidence that time from first courtship to copulation was influenced by ornamentation (but see discussion above). Another prediction of an amplifier function is that females should make fewer mistakes when assessing more ornamented males. Increased expression of an amplifier should lead to increased mating success of preferred males, but decreased mating success of unpreferred males (Hasson, 1989; Galvan and Sanz, 2008). Given the importance of courtship rate for male mating success in S. stridulans, this prediction would translate into the following: males with high courtship rates should have a mating advantage if they are highly ornamented, while males with low courtship rates should have a mating disadvantage if they are similarly ornamented. Interestingly, these predictions are the exact opposite of our observed mating patterns. At high courtship rates, more ornamented males seemed to be at a mating disadvantage compared to males with similar courtship rates but less ornamentation, while at low courtship rates males with more ornamentation had a mating advantage over similarly courting males with less ornamentation. Taken together, our results do not support an amplifier function.

\section{Content Effects}

In wolf spiders, foreleg ornamentation is fixed at maturation (Foelix 1996) and reflects a male's developmental history (Uetz et al., 2002; Hebets et al., 2008; Shamble et al., 2009). Courtship rate, in contrast, is probably more variable and dynamic, potentially influenced by both a male's current condition and motivation (Hoefler et al. 2009). In addition, courtship expression may be influenced by external factors, such as the presence of predators or the signaling environment (e.g. Endler, 1987; Candolin, 1997; Koga et al., 1998). Thus, one possibility is that each courtship component could provide females with different information, one reflecting a male's success in his juvenile environment and the other reflecting a male's success in, or reaction to, his current environment. One could imagine various ways in which mating decisions could be based upon this combination of information. For example, given our results, females may relax their criteria for courtship rate if a male can demonstrate past foraging success. Past foraging success reflects success in the juvenile environment, presumably the same environment that offspring will eventually face. The breeding season of S. stridulans begins in early to mid-June, with spiderlings emerging by mid-August. As such, juveniles overwinter and finish their growth and maturation the following spring. Assuming that relevant environmental changes happen with season and that little migration occurs, foreleg ornamentation may be indicative of offspring success in the juvenile environment, and thus may be an important basis for mate choice. Although these specific hypotheses remain to be tested, the combination of information contained in the ornament and the courtship rate may be the basis of female mate choice decisions. Future work examining female preferences to various trait combinations and variation in these preferences across females and environments would certainly be fruitful.

Results from our first two experiments lend support to the hypothesis that the significant interaction observed between ornamentation and courtship rate relates to the information content of these components. In these experiments, the natural variation in foreleg phenotype was concealed, at least in subsets of males (i.e. unornamented treatments and artificially ornamented treatments), resulting in an artificial decoupling of traits and their respective content. If females choose males based upon the combined information of ornamentation and courtship rate, a decoupling of this information would make it difficult, if not impossible, to detect an interaction; and no interaction was detected.

\section{Costs of Ornamentation}

In addition to the suggested benefit of relaxing a male's dependence on courtship rate for mating success, ornamentation also appears to carry a mating cost: a reduced probability of mating for highly ornamented males courting at a high rate. Figure 3 illustrates the pattern that a male in the least ornamented quartile could virtually be guaranteed a mating if it courted above $\sim 1.3$ double taps/min. In contrast, for the more ornamented males in the middle two quartiles, $100 \%$ mating success was only achieved at courtship rates well above 
4 double taps/min (almost four times that of the least ornamented males). Finally, for the most ornamented quartile of males, mating success was never guaranteed. We propose, as one possibility, that this pattern of increased courtship rate thresholds for $100 \%$ mating success for males of increasing ornamentation may be driven by female startling (e.g. Patricelli et al. 2002). Despite the fact that female wolf spiders are known to cannibalize males (Hebets, 2003; Persons and Uetz, 2005; Wilder and Rypstra, 2008), they will also jump away in response to aggressive male courtship (E.A.H., personal observation). Mature male Schizocosa will continuously attempt to mount unreceptive females (Hebets, 2003; Hebets and Vink, 2007), and sexual interactions in wolf spiders can frequently be aggressive (Hebets, 2007; Johns et al., 2009; Wilgers et al., 2009). For example, recent evidence has shown that male $S$. ocreata use their fangs during sexual encounters with females, sometimes resulting in female hemolymph loss (Johns et al. 2009), highlighting a significant cost to mating with aggressive males. Sexual aggressiveness has also been linked to foreleg ornamentation in at least one population of Schizocosa, with more ornamented males engaging in more sexually aggressive behavior ( $\mathrm{He}-$ bets \& Vink 2007). Unfortunately, this study did not quantify female startle responses, but female startling in response to aggressive courtship may help explain why highly ornamented $S$. stridulans males that court at a high rate are not the most successful males.

In summary, like males of many species, mature male Schizocosa stridulans develop conspicuous secondary sexual traits despite no previously recognized overt female preference for them. Here, we uncover an interaction between courtship components that aids in explaining the evolution and function of such previously enigmatic ornaments. Although the mechanism underlying this particular interaction remains unknown, this study adds to a growing literature demonstrating the importance of intersignal interactions (Kelly and Marples, 2004; Hebets, 2005; Hebets and Papaj, 2005; Kulahci et al., 2008; Smith et al., 2009), and emphasizes the value of inclusive analyses of complex display function. In addition, our study underscores the importance of female mate choice for courtship performance and provides results consistent with the hypothesis that ornamentation evolved secondarily to enhance a male's apparent motor performance (Byers et al. 2010).

Acknowledgments - We thank Kasey Fowler-Finn, Amy Nicholas and Gail Stratton for aid in spider collecting; Gail Stratton and Pat Miller for providing food, lodging and wonderful company during collections, and Jenny Bushing for providing spider maintenance. High School students Tawny Bernt and Thecla Shoeneberger collected part of the data for experiment 3 during Spider Camp 2009, a camp offered during Big Red Summer Academic Camps through Nebraska's 4-H extension. The graphical representation and resulting interpretation of the uncovered interaction was made possible by the suggestions of Chad Brassil. Earlier drafts of this manuscript were greatly improved through invaluable comments provided by Laura Sullivan-Beckers as well as members of the Basolo, Wagner, and Hebets lab groups, four anonymous referees and the handling editor for Animal Behaviour, Mark Bee. This work was supported by a National Science Foundation CAREER grant to E.A.H. (I.O.S-0934990), and the collaboration with Rafael Rodriguez was facilitated by a National Evolutionary Synthesis Center working group.

\section{References}

Ahtiainen et al., 2004 • J. J. Ahtiainen, R. V. Alatalo, R. Kortet, and M. J. Rantala, Sexual advertisement and immune function in an arachnid species (Lycosidae), Behavioral Ecology 15 (2004), pp. 602-606.

Ahtiainen et al., 2005 - J. J. Ahtiainen, R. V. Alatalo, R. Kortet, and M. J. Ran- tala, A trade-off between sexual signaling and immune function in a natural population of the drumming wolf spider Hygrolycosa rubrofasciata, Journal of Evolutionary Biology 18 (2005), pp. 985-991.

Andersson, 1994 - M. Andersson, Sexual Selection, Princeton University Press, Princeton, New Jersey (1994).

Backwell et al., 1999 - P. R. Y. Backwell, M. D. Jennions, J. H. Christy, and N. I. Passmore, Female choice in the synchronously waving fiddler crab Uca annulipes, Ethology 105 (1999), pp. 415-421.

Bro-Jorgensen, 2010 $-\mathrm{J}$. Bro-Jorgensen, Dynamics of multiple signaling systems: Animal communication in a world in flux, Trends in Ecology \& Evolution 25 (2010), pp. 292-300.

Brodie, $1992 \cdot$ E. D. Brodie, Correlational selection for color pattern and antipredator behavior in the garter snake Thamnophis ordinoides, Evolution $\mathbf{4 6}$ (1992), pp. 1284-1298.

Byers et al., 2010 - J. Byers, E. Hebets, and J. Podos, Female mate choice based upon male motor performance, Animal Behaviour 79 (2010), pp. 771-778.

Candolin, 1997 - U. Candolin, Predation risk affects courtship and attractiveness of competing threespine stickleback males, Behavioral Ecology and Sociobiology 41 (1997), pp. 81-87.

Candolin, 2003 - U. Candolin, The use of multiple cues in mate choice, Biological Reviews 78 (2003), pp. 575-595.

Cohen, 1988 - J. Cohen, Statistical Power Analysis for the Behavioral Sciences (2nd ed.), L. Erlbaum, Hillsdale, New Jersey (1988).

Darwin, 1871 - C. Darwin, The Descent of Man, and Selection in Relation to Sex, J. Murray, London (1871).

Delaney et al., 2007 - K. J. Delaney, J. A. Roberts, and G. W. Uetz, Male signaling behavior and sexual selection in a wolf spider (Araneae: Lycosidae): A test for dual functions, Behavioral Ecology and Sociobiology 62 (2007), pp. $67-75$.

Elias et al., 2006 - D. O. Elias, N. Lee, E. A. Hebets, and A. C. Mason, Seismic signal production in a wolf spider: Parallel versus serial multicomponent signals, Journal of Experimental Biology 209 (2006), pp. 1079-1084.

Endler, 1987 - J. A. Endler, Predation, light-intensity and courtship behaviour in Poecilia reticulata (Pisces, Poeciliidae), Animal Behaviour 35 (1987), pp. $1376-1385$.

Foelix, 1996 - R. Foelix, Biology of Spiders (2nd ed.), Oxford University Press, New York (1996).

Framenau and Hebets, 2007 - V. W. Framenau and E. A. Hebets, A review of leg ornamentation in male wolf spiders, with the description of a new species from Australia, Artoria schizocoides (Araneae, Lycosidae), Journal of Arachnology 35 (2007), pp. 89-101.

Galvan and Sanz, 2008 - I. Galvan and J. J. Sanz, The cheek plumage patch is an amplifier of dominance in great tits, Biology Letters 4 (2008), pp. 12-15.

Gerhardt and Huber, 2002 - H. C. Gerhardt and F. Huber, Acoustic Communication in Insects and Anurans, University of Chicago Press, Chicago (2002).

Gibson and Uetz, 2008 • J. S. Gibson and G. W. Uetz, Seismic communication and mate choice in wolf spiders: Components of male seismic signals and mating success, Animal Behaviour 75 (2008), pp. 1253-1262.

Hasson, 1989 - O. Hasson, Amplifiers and the handicap principle in sexual selection: A different emphasis, Proceedings of the Royal Society B 235 (1989), pp. 383-406.

Hebets, 2003 - E. Hebets, Subadult experience influences adult mate choice in an arthropod: Exposed female wolf spiders prefer males of a familiar phenotype, Proceedings of the National Academy of Sciences, U.S.A. 100 (2003), pp. 13390-13395.

Hebets, 2005 - E. A. Hebets, Attention-altering interaction in the multimodal courtship display of the wolf spider Schizocosa uetzi, Behavioral Ecology 16 (2005), pp. 75-82.

Hebets, 2007 - E. A. Hebets, Subadult female experience does not influence species recognition in the wolf spider Schizocosa uetzi Stratton 1997, Journal of Arachnology 35 (2007), pp. 1-10.

Hebets, 2008 - E. A. Hebets, Seismic signal dominance in the multimodal courtship display of the wolf spider Schizocosa stridulans Stratton 1991, Behavioral Ecology 19 (2008), pp. 1250-1257.

Hebets and Papaj, $2005 \cdot$ E. A. Hebets and D. R. Papaj, Complex signal function: Developing a framework of testable hypotheses, Behavioral Ecology and Sociobiology 57 (2005), pp. 197-214.

Hebets and Uetz, 2000 • E. A. Hebets and G. W. Uetz, Leg ornamentation and the efficacy of courtship display in four species of wolf spider (Araneae: Lycosidae), Behavioral Ecology and Sociobiology 47 (2000), pp. 280-286.

Hebets and Vink, 2007 - E. A. Hebets and C. J. Vink, Experience leads to preference: Experienced females prefer brush-legged males in a population of syntopic wolf spiders, Behavioral Ecology 18 (2007), pp. 1010-1020.

Hebets et al., 2006 - E. A. Hebets, K. Cuasay, and P. K. Rivlin, The role of visual ornamentation in female choice of a multimodal male courtship display, Ethology 112 (2006), pp. 1062-1070.

Hebets et al., 2008 • E. A. Hebets, J. Wesson, and P. S. Shamble, Diet influences mate choice selectivity in adult female wolf spiders, Animal Behaviour $\mathbf{7 6}$ (2008), pp. 355-363. 
Hoback and Wagner, 1997 • W. W. Hoback and W. E. Wagner, The energetic cost of calling in the variable field cricket, Gryllus lineaticeps, Physiological Entomology 22 (1997), pp. 286-290.

Hoefler, 2008 - C. D. Hoefler, The costs of male courtship and potential benefits of male choice for large mates in Phidippus clarus (Araneae, Salticidae), Journal of Arachnology 36 (2008), pp. 210-212.

Hoefler et al., 2009 - C. D. Hoefler, A. L. Carlascio, M. H. Persons, and A. L. Rypstra, Male courtship repeatability and potential indirect genetic benefits in a wolf spider, Animal Behaviour 78 (2009), pp. 183-188.

Hoglund et al., 1992 - J. Hoglund, J. A. Kalas, and P. Fiske, The costs of secondary sexual characters in the lekking great snipe (Gallinago media), Behavioral Ecology and Sociobiology 30 (1992), pp. 309-315.

Johns et al., 2009 • J. L. Johns, J. A. Roberts, D. L. Clark, and G. W. Uetz, Love bites: Male fang use during coercive mating in wolf spiders, Behavioral Ecology and Sociobiology 64 (2009), pp. 13-18.

Kelly and Marples, 2004 D. J. Kelly and N. M. Marples, The effects of novel odour and colour cues on food acceptance by the zebra finch, Taeniopygia guttata, Animal Behaviour 68 (2004), pp. 1049-1054.

Kodric-Brown and Nicoletto, 2001 - A. Kodric-Brown and P. F. Nicoletto, Female choice in the guppy (Poecilia reticulata): The interaction between male color and display, Behavioral Ecology and Sociobiology 50 (2001), pp. 346-351.

Koga et al., 1998 - T. Koga, P. R. Y. Backwell, M. D. Jennions, and J. H. Christy, Elevated predation risk changes mating behaviour and courtship in a fiddler crab, Proceedings of the Royal Society B 265 (1998), pp. 1385-1390.

Kotiaho, 2000 - J. S. Kotiaho, Testing the assumptions of conditional handicap theory: Costs and condition dependence of a sexually selected trait, Behavioral Ecology and Sociobiology 48 (2000), pp. 188-194.

Kotiaho et al., 1998a - J. Kotiaho, R. V. Alatalo, J. Mappes, S. Parri, and A. Rivero, Male mating success and risk of predation in a wolf spider: A balance between sexual and natural selection?, Journal of Animal Ecology $\mathbf{6 7}$ (1998), pp. 287-291.

Kotiaho et al., 1998b • J. S. Kotiaho, R. V. Alatalo, J. Mappes, M. G. Nielsen, S. Parri, and A. Rivero, Energetic costs of size and sexual signaling in a wolf spider, Proceedings of the Royal Society B 265 (1998), pp. 2203-2209.

Kulahci et al., 2008 - I. G. Kulahci, A. Dornhaus, and D. R. Papaj, Multimodal signals enhance decision making in foraging bumble-bees, Proceedings of the Royal Society B 275 (2008), pp. 797-802.

Lande and Arnold, 1983 - R. Lande and S. Arnold, The measurement of selection on correlated characters, Evolution 37 (1983), pp. 1210-1226.

Lindstrom et al., 2006 • L. Lindstrom, J. J. Ahtiainen, J. Mappes, J. S. Kotiaho, A. Lyytinen, and R. V. Alatalo, Negatively condition dependent predation cost of a positively condition dependent sexual signaling, Journal of Evolutionary Biology 19 (2006), pp. 649-656.

Lomborg and Toft, 2009 - J. P. Lomborg and S. Toft, Nutritional enrichment increases courtship intensity and improves mating success in male spiders, Behavioral Ecology 20 (2009), pp. 700-708.

Loyau et al., 2005 • A. Loyau, M. Saint Jalme, C. Cagniant, and G. Sorci, Multiple sexual advertisements honestly reflect health status in peacocks (Pavo cristatus), Behavioral Ecology and Sociobiology 58 (2005), pp. 552-557.

Loyau et al., 2008 • A. Loyau, M. Petrie, M. Saint Jalme, and G. Sorci, Do peahens not prefer peacocks with more elaborate trains?, Animal Behaviour $\mathbf{7 6}$ (2008), pp. e5-e9.

McClintock and Uetz, 1996 - W. J. McClintock and G. W. Uetz, Female choice and pre-existing bias: Visual cues during courtship in two Schizocosa wolf spiders (Araneae: Lycosidae), Animal Behaviour 52 (1996), pp. 167-181.

Madsen et al., 2004 • V. Madsen, T. J. S. Balsby, T. Dabelsteen, and J. L. Osorno, Bimodal signaling of a sexually selected trait: Gular pouch drumming in the magnificent frigatebird, Condor 106 (2004), pp. 156-160.

Mappes et al., 1996 - J. Mappes, R. V. Alatalo, J. Kotiaho, and S. Parri, Viability costs of condition-dependent sexual male display in a drumming wolf spider, Proceedings of the Royal Society B 263 (1996), pp. 785-789.

Matsumasa and Murai, 2005 - M. Matsumasa and M. Murai, Changes in blood glucose and lactate levels of male fiddler crabs: Effects of aggression and claw waving, Animal Behaviour 69 (2005), pp. 569-577.

Murai and Backwell, 2006 - M. Murai and P. R. Y. Backwell, A conspicuous courtship signal in the fiddler crab Uca perplexa: Female choice based on display structure, Behavioral Ecology and Sociobiology 60 (2006), pp. 736-741.

Nakagawa and Cuthill, $2007 \cdot$ S. Nakagawa and I. C. Cuthill, Effect size, confidence interval and statistical significance: A practical guide for biologists, Biological Reviews 82 (2007), pp. 591-605.

Norton and Uetz, 2005 - S. Norton and G. W. Uetz, Mating frequency in Schizocosa ocreata (Hentz) wolf spiders: Evidence for a mating system with female monandry and male polygyny, Journal of Arachnology 33 (2005), pp. $16-24$

Parri et al., 2002 - S. Parri, R. V. Alatalo, J. S. Kotiaho, J. Mappes, and A. Rivero, Sexual selection in the wolf spider Hygrolycosa rubrofasciata: Female preference for drum duration and pulse rate, Behavioral Ecology 13 (2002), pp. 615-621.

Patricelli et al., 2002 - G. L. Patricelli, J. A. C. Uy, G. Walsh, and G. Borgia, Male displays adjusted to female's response: Macho courtship by the satin bowerbird is tempered to avoid frightening the female, Nature 415 (2002), pp. 279-280.

Persons and Uetz, 2005 - M. H. Persons and G. W. Uetz, Sexual cannibalism and mate choice decisions in wolf spiders: Influence of male size and secondary sexual characters, Animal Behaviour 69 (2005), pp. 83-94.

Petrie et al., 1991 - M. Petrie, T. Halliday, and C. Sanders, Peahens prefer peacocks with elaborate trains, Animal Behaviour 41 (1991), pp. 323-331.

Prestwich and O'Sullivan, 2005 - K. N. Prestwich and K. O'Sullivan, Simultaneous measurement of metabolic and acoustic power and the efficiency of sound production in two mole cricket species (Orthoptera: Gryllotalpidae), Journal of Experimental Biology 208 (2005), pp. 1495-1512.

Rosenthal, 1991 - R. Rosenthal, Meta-analytic Procedures for Social Research, Sage, Newbury Park (1991).

Rundus et al., 2010 - A. S. Rundus, R. D. Santer, and E. A. Hebets, Multimodal courtship efficacy of Schizocosa retrorsa wolf spiders: Implications of an additional signal modality, Behavioral Ecology 21 (2010), pp. 701-707.

Rundus et al., 2011 - A. S. Rundus, L. Sullivan-Beckers, D. J. Wilgers, and E. A Hebets, Females are choosier in the dark: Environment-dependent reliance on courtship components and its impact on fitness, Evolution 65 (2011), pp. 268-282.

Rutledge et al., 2010 - J. M. Rutledge, A. Miller, and G. W. Uetz, Exposure to multiple sensory cues as a juvenile affects adult female mate preferences in wolf spiders, Animal Behaviour 80 (2010), pp. 419-426.

Rypstra et al., 2003 - A. L. Rypstra, C. Wieg, S. E. Walker, and M. H. Persons, Mutual mate assessment in wolf spiders: Differences in the cues used by males and females, Ethology 109 (2003), pp. 315-325.

Saether et al., 2000 - S. A. Saether, P. Fiske, J. A. Kalas, and J. M. Gjul, Females of the lekking great snipe do not prefer males with whiter tails, Animal Behaviour 59 (2000), pp. 273-280.

Scheffer et al., 1996 • S. J. Scheffer, G. W. Uetz, and G. E. Stratton, Sexual selection, male morphology, and the efficacy of courtship signaling in two wolf spiders (Araneae: Lycosidae), Behavioral Ecology and Sociobiology 38 (1996), pp. 17-23.

Shamble et al., 2009 - P. S. Shamble, D. J. Wilgers, K. A. Swoboda, and E. A. Hebets, Courtship effort is a better predictor of mating success than ornamentation for male wolf spiders, Behavioral Ecology 20 (2009), pp. $1242-1251$.

Sinervo and Svensson, 2002 - B. Sinervo and E. Svensson, Correlational selection and the evolution of genomic architecture, Heredity 89 (2002), pp. 329-338.

Smith et al., 2009 • C. L. Smith, D. A. Van Dyk, P. W. Taylor, and C. S. Evans, On the function of an enigmatic ornament: Wattles increase the conspicuousness of visual displays in male fowl, Animal Behaviour 78 (2009), pp. $1433-1440$.

Stratton, 1991 - G. E. Stratton, A new species of wolf spider, Schizocosa stridulans (Araneae, Lycosidae), Journal of Arachnology 19 (1991), pp. 29-39.

Stratton, 1997 - G. E. Stratton, A new species of Schizocosa from the southeastern USA (Araneae, Lycosidae), Journal of Arachnology 25 (1997), pp. 84-92.

Stratton, 2005 - G. E. Stratton, Evolution of ornamentation and courtship behavior in Schizocosa: Insights from a phylogeny based on morphology (Araneae, Lycosidae), Journal of Arachnology 33 (2005), pp. 347-376.

Takahashi et al., 2008 • M. Takahashi, H. Arita, M. Hiraiwa-Hasegawa, and T. Hasegawa, Peahens do not prefer peacocks with more elaborate trains, Animal Behaviour 75 (2008), pp. 1209-1219.

Uetz and Norton, $2007 \cdot$ G. W. Uetz and S. Norton, Preference for male traits in female wolf spiders varies with the choice of available males, female age, and reproductive state, Behavioral Ecology and Sociobiology 61 (2007), pp. $631-641$

Uetz and Roberts, 2002 - G. W. Uetz and J. A. Roberts, Multisensory cues and multimodal communication in spiders: Insights from video/audio playback studies, Brain, Behavior and Evolution 59 (2002), pp. 222-230.

Uetz et al., 2002 • G. W. Uetz, R. Papke, and B. Kilinc, Influence of feeding regime on body size, body condition and a male secondary sexual character in Schizocosa ocreata wolf spiders (Araneae, Lycosidae): Condition-dependence in a visual signaling trait, Journal of Arachnology 30 (2002), pp. 461-469.

Uetz et al., 2009 • G. W. Uetz, J. A. Roberts, and P. W. Taylor, Multimodal communication and mate choice in wolf spiders: Female response to multimodal versus unimodal signals, Animal Behaviour 78 (2009), pp. 299-305.

Westneat, 2006 - D. F. Westneat, No evidence of current sexual selection on sexually dimorphic traits in a bird with high variance in mating success, American Naturalist 167 (2006), pp. E171-E189.

Wilder and Rypstra, 2008 - S. M. Wilder and A. L. Rypstra, Sexual size dimorphism predicts the frequency of sexual cannibalism within and among species of spiders, American Naturalist 172 (2008), pp. 431-440.

Wilgers et al., 2009 • D. J. Wilgers, A. C. Nicholas, D. H. Reed, G. E. Stratton, and E. A. Hebets, Condition-dependent alternative mating tactics in a sexually cannibalistic wolf spider, Behavioral Ecology 20 (2009), pp. 891-900.

Zuk et al., $1995 \cdot$ M. Zuk, S. L. Popma, and T. S. Johnsen, Male courtship displays, ornaments and female mate choice in captive red jungle fowl, Behaviour 132 (1995), pp. 821-836. 